\title{
Apuntes sobre criminología feminista
}

Luz María Durán Moreno*

SUMARIO: i. Introduc ción. II. Antecedentes III. El desa rollo de la Criminología Feminista. IV. Realismo de Izquierda y Criminología Feminista. V. Nuevos enfoques de la Criminología Feminista. VI. Conclusiones. VII. Bibliografía

RESUMEN: La criminología ha desarrollado un importante trabajo en la explicación de la criminalidad, en el que han confluido principalmente los estudios sobre los hombres delincuentes, desarrollando escasos trabajos sobre la conducta criminal de lasmujeres. Es a partir de los años setenta, con la tesis de la liberación que se cuestiona sobre el papel de las diferencias de género en la explicación de las marcadas diferencias en la participación criminal de hombres y mujeres. El interés por este tema permite desarrollar estudios y políticas más enfocados hacia la victimización de las mujeres. En los años noventa inicia una visión altema que cuestiona la necesidad de abordar este tema, ya no teniendo como punto de referencia la conducta delictiva del varón, sino recumiendo a conceptos y métodos que se encuentran fuera del discurso criminológico, como la perspectiva de género; teniendo presente también la necesidad de los estudios sobre masculinidad.

\section{Introduc ción}

En las últimas décadas, la tasa de delincuencia femenina ha tenido un crecimiento y una variabilidad en las conductas delictivas. A los delitos típic os cometidos por este grupo se han incorporado nuevas actividades delic tivas como: asalto a banco, secuestro, extorsión y delitos contra la salud. Delitos que hasta hace poco estuvieron tradicionalmente asociados con el género masculino, precisamente por la violencia implícita y el modus operandi que conlleva su ejecución.

El conocimiento generalizado sobre esta problemática es que la mayońa de las mujeres encarceladas proviene de sectores de la población económica y socialmente desfavorecida y que permanece encarcelada por delitos típicos que carecen de poder, también que son mujeres que han vivido en la pobreza y han sido violentadas la mayor parte de sus vidas. A este

\footnotetext{
* Profesora Investigadora de la Universidad de Sonora, Estudiante del Doctorado en Criminología en la Universidad de Castilla-La Mancha, España.
} 
conocimiento habría que incorporar el a nálisis de la conducta criminal de las mujeres a partir de enfoques distintos hasta los ahora abordados, ¿las diferencias de género explican las diferencias de participación en la criminalidad?

Reflexionar sobre este tema y discemir sobre el papel que ha ocupado en el desarrollo de las teońas criminológicas y de las investigaciones que se han realizado, así como sobre las perspectivas desde las cuales ha sido abordado este problema, exige entrar a un tema complejo y, porque no decirlo, cargado de prejuiciosos ideológicos, tal como se evidencia en este desa rollo evolutivo. En el presente documento se describen las tres etapas de la criminología feminista, revisando en cada una de ellas la situación que guarda este tema en el marco de la criminología en general.

La primera etapa se caracteriza por algunos someros estudios sobre c rimina lidad femenina en las primeras décadas del siglo XX, en el marco de la criminología tradicional. Las teorías y hallazgos de la criminalidad masculina eran aplicables a las mujeres y reflejaban una imagen machista de la mujer delincuente y de la mujer en general, que fortalecían la imagen de la mujer sumisa, pasiva e inferior.

La segunda etapa, durante los años setenta y ochenta, se desarrolla la Tesis de la Liberación, en el marco de la Nueva Criminología y el Realismo de Izquierda, es en este periodo cuando se habla ya propiamente de Criminología Feminista.

Y en la tercera etapa, a partir de los años noventa, surgen importantes reflexiones y cuestiona mientos sobre los estudios desarrolla dos en este tema y sobre la agenda por desarrollar en los próximos años. El patriarcado se incorpora como un elemento central en los estudios y están en proceso de construc ción las explic a ciones criminológic as con perspectiva de género. 


\section{Antecedentes}

La criminalidad de la mujer ha sido ignorada por la Criminología, los estudios sobre la conducta criminal de las mujeres han sido escasos, teniendo como razón principal el reducido número de población femenina en las cárceles. A finales del siglo $X I X$, principios y mediados del siglo $X X$, sólo un pequeño número de escritos hablaron de este tema; todos coincidían en buscar diferencias entre las mujeres delincuentes y las no delincuentes. Como resultados se identifican dos clases de mujeres: las mujeres buenas y las mujeres malas. Alrededor de esta asunción se asumía también que "el crimen era resultado de la voluntad individual, de una elección individual"; por lo tanto, las mujeres eran libres para elegir la no delincuencia, invalidando la influencia del mundo social, económico y político.

Cesar Lombroso en "The female ofender" (1903-1920) postula que la delincuencia femenina es una tendencia inherente a las mujeres, que en efecto no habían evolucionado apropiadamente hacia mujeres femeninas con refinamientos morales. Dio argumentos psicológicos para argumentar que las mujeres delincuentes eran atavistas biológicas ${ }^{1}$ (incluyendo aquí caractenístic as craneales y faciales, a ltura, pelo osc uro, color de piel, etc.).

También caracterizaba a las mujeres por inmovilidad fisiológica, pasividad psicológica, predisposición fría y calculadora. Las mujeres criminales eran más masculinas que femeninas, podían pensar como hombres, mientras que las "buenas mujeres" no. También las delincuentes eran más fuertes en algunos aspectos que los hombres y se podían ajustar más fá cilmente que los hombres al dolor físic o y mental, las mujeres delincuentes eran anomales. Pero no solo eso, Lombroso y Ferrero ${ }^{2}$, señalarían que son doblemente

\footnotetext{
${ }^{1}$ Describir el atavismo de Lombroso

2 Almeda, E., Mujeres encarceladas, capítulo 1: Las cárceles femeninas en España, Edit. Ariel, Barcelona, España, 2003
} 
prejuiciosas comparadas con los hombres y que su doble infracción de las leyes comporta que a las mujeres criminales se las puede considerar como un "monstruo".

W. I. Thomas en sus obras "Sex and Society" (1907) y "The undjusted girl" (1923), propone dos visiones distinta s en este tema. En su primera obra, pone el énfasis en las diferencias fisiológicas y psicológicas; los hombres son destructivos de energía y las mujeres guardan energía como las plantas, son menos activas y más conservadoras. Esta diferencia ha contribuido a un relativo declive en el status de las mujeres, especialmente en las sociedades civilizadas. En otro momento explicó las diferencias en la criminalidad a causa de la pérdida de la libertad sexual de la mujer. Las mujeres bajo la monogamia tuvieron que confinar su conducta sexual a ser mujeres y madres y ajustarse al hecho de ser tratadas como propiedad controlada por los hombres. En esencia la monogamia y la castidad se convirtieron en una forma de acomodo para las necesidades básicas del hombre. Su postura se enfocó a considerar la delincuencia femenina como nomal bajo deteminadas circunstancias, dadas ciertas asunciones sobre la naturaleza de la mujer. Y respecto al castigo a loscriminales, su actitud es la defensa de la rehabilitación y la prevención.

La forma de prevenir que la mujer delinquiese era que se ajustasen a la situación que les toca vivir como mujeres. Por eso mas mujeres de clase media delinquen poco, éstas han sido socia liza das para aceptar su situa ción y valorar su castidad como una inversión. Las mujeres de clase baja no se han socializado de esta manera, no han sido socializadas para suprimir su necesidad de seguridad y por lo tanto delinquen por deseo de excitación y nuevas experiencias.

Otra obra importante de la época es la de Otto Pollak, The criminality of women (1950), en la que también se exponen razones psicológicas. Las 
mujeres son inherentemente mentirosas a causa de estas razones3. Los hombres no pueden esconder sus errores sexuales o sus emociones sexuales ya que deben conseguir una erección para practicar el sexo. Las mujeres son, por tanto, mentirosas, engañosas innatamente. Cuando esta naturaleza femenina se combina con oportunidades domésticas como sirvientas, enfemeras, profesoras y amas de casa, esa naturaleza engañosa les pemite delinquir de forma no detectable.

Otro elemento que incorpora Pollak en el análisis es el tratamiento que se le da a la mujer en el ámbito de la administración de justicia, exponiendo la tesis de la caballerosidad. Las mujeres reciben un trato diferente en las justicia porque seducen a los jueces y policías y, en consecuencia, éstos se muestran mas benévolos con ellas que con los hombres, lo que hace que las cifras de sus crímenes se escondan. El y muchos otros teóricos pioneros, explic aron los crímenes ec onómic os femeninos por motivos sexua les de base psicológica y fisiológica. No consideró que las mujeres delincuentes suelen ser pobres o que han dejado de lado definiciones de roles de mujer chovinistas, clasistas y ra c istas.

Por otra parte, la actitud patemalista del sistema de administración de justicia, en el trato hacia las mujeres, se debía a que estas eran vistas como personas desprotegidas y desfavorecidas que deberían ser juzgadas con menos rigor que los hombres. Pero la Criminología Feminista ha criticado con dureza esta tesis, porque como se ha visto en las esta dísticas delictivas éstas tienden a cometer menos delitos y de menor gravedad, por eso la poca participación en las estadísticas delictivas. Sin embargo, otros autores oponen argumentos a la anterior tesis, Rutter y Giller 4 concluyeron que durante la década de 1970, las jóvenes solían ser trata das por los tribunales algo más severamente que los jóvenes. Así, ellas tenían más probabilidades de comparecer ante los Tribunales por asuntos no penales como "estar en

\footnotetext{
${ }^{3}$ Citado en Smart, Almeda, op. cit.

${ }^{4}$ Rutter, M., Guiller, H., La conducta antisocial de los jóvenes, 1983.
} 
peligro moral" o "fuera de control", se les llevaba a los tribunales por delitos menores. Eso puede implicar que las chicas jóvenes son perseguidas de manera desproporcionada por hechos leves, que en el caso de los chicos pasańa sin mayor relevancia como travesuras propias de la edad. En este tenor, Elena Azaola ${ }^{5}$ concluye en su trabajo sobre las mujeres recluidas en las cárceles de la ciudad de México, que las mujeres procesadas por delitos cometidos contra la familia, como homicidios de hijos y parejas, son más duramente condenadas que los hombrespor el mismo tipo de delitos.

Sobre la participación de las mujeres en las bandasjuveniles, Urteaga y Pozo 6 señalan que su participación al interior de las bandas es marginal, pasiva y secundaria. Dicha caracterización se vincula con la reproducción de las pautas generales de subordina ción de las mujeres en la sociedad. Su falta de participación y la calidad de la misma se vincula a diversos fenómenos que se refuerzan entre sí: los estereotipos femeninos existentes a nivel social que condenan la presencia de la mujer en la calle, y más si se trata de jóvenes, solteras, con atuendos poco comunes o en actividades no tradicionales vinculadas a su género. Esta cuestión se expresa a nivel familiar, de los vecinos y la comunidad en general, en un estricto control sobre ellas en términos de movilidad espacial, mucho mayor que en el caso de los jóvenes7.

\section{E desamollo de la Criminología Feminista}

En el campo de la Criminología, el feminismo ${ }^{8}$ crítica a las teorías tradicionales de reflejar una imagen machista de la mujer delincuente y de la mujer en general, de dar una imagen de la mujer sumisa, pasiva e inferior.

\footnotetext{
${ }^{5}$ Azaola, Elena, El delito de ser mujer. Hombres y mujeres homicidas en la ciudad de México: historias de vida, Edit. Plaza y Valdez, México, 1996.

${ }^{6}$ Urtega, C., Pozo, M., “Flores de asfalto. Las chavas en las culturas juveniles” en Jóvenes, Revista de estudios sobre juventud, Ciudad de México, cuarta época, año 1, Num. 2, 1996.

${ }^{7}$ Arteaga, Catalina, "Identidades y relaciones de género de chavos banda en la Ciudad de México. Un estudio de caso exploratorio en la delegación Tlalpan”, 2000. www.clacso.org

${ }^{8}$ El feminismo es un movimiento social y político preocupado por la igualdad de las mujeres, por la equidad del género. Históricamente se pueden distinguir tres olas en el feminismo: 1) el movimiento sufragista de principios del siglo XX, 2) el movimiento social y de lucha por los derechos civiles y humanos de los años sesenta (en
} 
La Criminología tradicional se ha movido entre no tomar en cuenta la delincuencia cometida por las mujeres o bien considerar que las teorías y hallazgos sobre hombres eran aplicables a las mujeres. Pero la desatención no se ha limitado a las causas de la Criminología Feminista sino que ha incluido los controles que han experimentado las mujeres para que su comportamiento sea respetuoso con las nomas.

La Criminología feminista comenzó con una hipótesis muy prometedora: si las mujeres comenten menos delitos, quizá haya algo en el género, en las características de las mujeres, que nos ayude a encontrar las causas del delito, pero desafortunadamente esta tesis no ha tenido la continuidad esperada 9 .

A principios de los años 70 apareció lo que se conoce como la Tesis de la Liberación, que se refeńa a las siguientes cuestiones: ¿cómo es que los hombres delinquen más que las mujeres? ¿Se trata de diferencias esenciales o que pueden disminuir con el cambio de las circunstancias? ${ }^{10}$.

La tesis sobre las diferencias en la criminalidad entre hombres y mujeres postula que hasta ahora los hombres y las mujeres han venido desempeñando y ocupando distintos roles y posiciones sociales, de tal manera que las mujeres se han visto relegadas a un segundo plano. De este modo, según las mujeres vayan escalando posiciones en nuestra sociedad y aproximándose a los hombres de manera que las diferencias disminuyan con el paso del tiempo, y según las mujeres vayan viéndose de un modo menos subordinado a los hombres, entonces también se irán equiparando los

países como España y América Latina) y 3) la preocupación por la igualdad de las mujeres, como un movimiento heterogéneo.

${ }^{9}$ Rutter, M., Giller, H y Hagel, A., La conducta antisocial de los jóvenes, Edit. Cambridge University Press, Madrid, 1999, 352-385

${ }^{10}$ Serrano, Alfonso. Introducción a la Criminología,. UNED, 2da edic., Madrid, 2004. 
respectivos índices de delincuencia. Por otro lado, según se vayan aproximando las posiciones, ta mbién el sistema de administra ción de J usticia tenderá a tratarlos porigual.

En esta época aparecen dos libros controvertidos "Sister in Crime" de Freda Adler (1975) y "Women and Crime" de R. J. Simon (1975). Adler veía menos restric ciones de las mujeres y sus oportunidades en el mercado, dándole la oportunidad de ser tan violentas, codiciosas y propensas a la delincuencia como los hombres. Simon, por su parte, veía un aumento en los delitos contra la propiedad (no en delitos violentos) explicable por las mayores oportunidades que tienen en el trabajo para delinquir.

Sin embargo, Steffensmeir (1980), en su articulo "Trends in female delinquency" criticó las posturas anteriores argumentando que las mujeres cometerán más delitos pero la diferencia con los hombres sigue siendo mucha, cualquier cifra en los datos de las mujeres, por pequeño que sea en las cifras absolutas se ve como alto en los porcentajes a causa de que siempre ha sido muy baja. Solo vio aumentos en el robo, un tipo de delitos que siempre ha dado muchos números en las mujeres. Esto lo llevo al cuestionamiento de que si el incremento de las oportunidades -tal como lo proponían Simon y Adler- no explica el aumento del crimen femenino ¿qué lo hace?

Steffensmeir responde a esta pregunta a partir de dosargumentos: 1) hoy en día hay una gran oportunidad para que las mujeres delincan en comparación con los tiempos pasados, en delitos de poco dinero y fraude. Con el mercado actual se adviene una gran oportunidad para la mujer, que a cambio concede nuevas oportunidades para crímenes antiguos: robar en tiendas, cheques falsos y fraude de ta jetas. Estas oportunidades nuevas se asocian también con un aumento de la seguridad y el arresto, que aumenta la cifra de delitos de mujeres. Y 2) Las fuerzas de justicia y de seguridad hacia 
las mujeres están cambiando su actitud, y ahora están mas dispuestos a arrestary sentenciara mujeres.

Pero, tal como lo veremos en la siguiente etapa de la criminología, los libros de Adler y Simon ignoraron el impacto de las relaciones de poder, omitieron en el análisis el patriarcado como parte de la estructura social que pemite al hombre el control sobre la mujer (su trabajo y su sexualidad). Se olvidaron de estudia ry considera r esta otra perspectiva del a nálisis.

Después de estas autoras la siguiente generación de criminólogos y criminólogas feministas se centró en el patriarcado, ya no en la emancipación. Tesis que tuvo gran importancia porque focalizó la atención en la delincuencia femenina, que había sido ignorada por la criminología tradicional.

Para las feministas, el tema hoy día es lo penetrante de la dominación masculina en la sociedad patriarcal y su impacto sobre los delitos cometidos por y sobre las mujeres. Las diferencias de poder llevan a las mujeres a cometer crímenes que son "sin poder", como la prostitución y fraudes de pequeña escala. Estos crímenes traen poca satisfacción porque las mujeres están marginalizadas por la destitución económica. Por lo tanto, algunos delitos femeninos son una manifestación de ello y ayuda a reproducir la estratificación social de la sociedad. Un ejemplo del abordaje del crimen desde la perspectiva de género es la violencia intrafamiliar, el abuso sexual y la violación, como ejercicios del poder del hombre sobre las mujeres.

Como consecuencia de la perspectiva feminista se puso mayor atención a las víc timas y supervivientes de la violencia sexual y física, no sólo en el plano criminológico, sino también en los ámbitos político y social, sensibilizando sobre esta problemática y definiendo políticas pública de atención a las víc timas. 


\section{Realismo de Izquierda y Criminología Feminista}

La Nueva Criminología ${ }^{11}$ de finales de los años 60 y principios de los 80 recibió este nombre, llamada también criminología maxista, materialista y crítica, entre otras. Fue muy poderosa en cuanto a la crítica a la criminología tradicional, hasta el punto que redingir la estructura total del discurso concemiente al crimen y a la desviación. La primera tarea de los autores era demostrar que los estudios convencionales sobre crimen se amoldaban a teorías y paradigmas que asumían un monopolio sobre lo "correcto", lo "científico" y lo "deteminista" en cuanto al entendimiento de la naturaleza humana y del orden social.

Para la Nueva Criminología, el capitalismo es un orden social alienante y explotador, en el que la no igualdad está institucionalizada por una clase dominante $y$, en consecuencia, la delincuencia es una respuesta a los arreglos forzados, es un producto de la economía política. Bajo este sistema capitalista, la ley criminal está manipulada en beneficio de un grupo determinado, la delincuencia se definińa como políticas capitalistas e intereses que contribuyen a la miseria humana y a la deprivación de las personas de su potencial humano.

Los herederos hoy en día de la Criminología Crítica es el Realismo de Izquierda o Criminología Realista, con gran influencia Británica y Esta dounidense.

La Nueva Criminología o Criminología Radical se había centrado en el efecto del estado en la delincuencia, pero no había abordado el efecto del delito en la víctima. Este olvido fue muy grave porque debía haberse centrado en el triángulo "delincuente, víctima y estado", propio del objeto de estudio de la criminología. Ante las críticas y la nueva situación, se desarrolló un enfoque diferente, el Realismo de Izquierda, llamado así por el

\footnotetext{
${ }^{11}$ Larrauri, Elena, La herencia de la criminología crítica, Edit. Siglo XXI, España, 1992, p.102
} 
énfasis en los aspectos rea les del crimen. En este nuevo enfoque había una preocupación central que era que la nueva criminología había puesto demasiado énfasis en el estado, olvidando la etiología del crimen. El Realismo de Izquierda estaba preocupado explícitamente, aunque no exclusivamente, por los ońgenes, naturaleza e impacto del crimen en la clase obrera. Y un ejemplo de la preocupación por las víctimas es el énfasis en las perspectivas feministas. Se preocupaba por las mujeres víc timas, al igual que por el racismo, la brutalidad policial y otros temas. La particularidad de esta perspectiva es que se interesaba por las dimensiones del poder y de clase, de lascausas de la delincuencia y qué se puede haceral respecto.

\section{Nuevos enfóques de la Criminología Feminista}

Carol Smart y Maureen Cain apuntan hacia nuevas direcciones en la Criminología Feminista, criticando no sólo a la criminología tradicional, como lo hace la Nueva Criminología y el Realismo de Izquierda, sino incluso considerando limitadas las posibilidades que presentan estas últimas teorías para abordar en un lugar central los estudios de las mujeres.

Maureen Cain 12 propone a la criminología Feminista como una Criminología Transgresora, creadora de espacios "sólo de las mujeres", colocando en un lugar central los estudios de este género por razones políticas y teóricas. Transgrediendo la atadura del tejido del co-hombre, es decir, estudiando a las mujeres como las mujeres y comparando diferentes tipos de mujeres, en lugar de comparar hombres y mujeres, quitando la atención en el varón como la "vara de medir". Para ello se requiere empezar esta criminología transgresora fuera del discurso criminológico, porque éste no provee de herramientas para explorar los estudios de mujeres desde esta perspectiva.

La autora señala que sólo desde afuera, con la construcción social del género o con las experiencias de vidas de mujeres o con la estructura del

\footnotetext{
${ }^{12}$ Cain, Maureen, Towards transgression: New directions in feminist criminology. International Journal of the Sociology of Law, 18, 1990, pp.1-18
} 
espacio doméstico, es posible tener el sentido de lo que está pasando. Esto es posible, señala Cain, a partir de tres estrategias: la reflexividad, la deconstrucción y la re-construcción del discurso y de las prácticas. Es necesario preguntamos por ejemplo ¿Cómo el género se constituye en las cárceles, en las estaciones de policía, en las cortes? ¿Cómo estos sitios y modos de constitución del género se conectan con otros sitios y modos? ¿Cuáles son los efectos de estas prácticas para las mujeres, para los hombres y para la autorrea lización huma na?

La criminología tradicional, sin embargo, no se cuestiona sobre estos sitios, sobre estas instituciones, da por hecho que la ley y la administración así lo prevén. Así mientras la criminología liberal o radical siempre se ha preocupado por la clase social, raramente se ha cuestionado por las relaciones de clase y su constitución y re-constitución como pregunta central, más bien ha visto la lucha de clases como su preocupación central.

Maureen Cain aclara que en esta problemática extra-criminológica debemos re-introducir a los hombres, pero ya no en el sentido tradicional, sino preguntándose cómo la construcción social de la masculinidad se conecta con el hecho de que la mayoría de los delincuentes son y siempre han sido los hombres, no preguntarse esto es como si se considerasen nomales las propiedades criminógenas de la masculinidad. Esta es otra razón que da la autora de por qué las feministas deben transgredir la criminología misma para entender a los hombres y a las mujeres como ofensores, víctimas, demandadosy prisioneros.

Carol Smart ${ }^{13}$, en el marco del disc urso posmodemo, a firma que el feminismo está planteando preguntas significativas sobre el estado y el poder del conocimiento y formulando desafíos a las grandes teorizaciones que

\footnotetext{
${ }^{13}$ Smart, Carol, Law, crime and sexuality, Essays in Feminis, Edit. Sage Publications Ltd, London, 1995.
} 
imponen una unifomidad de perspectivas e ignoran la inmensa diversidad de mujeres y hombres.

El Posmodemismo es un movimiento muy heterogéneo que se ha propuesto una serie de críticas a la modemidad y sus asunciones, sobre todo a la exaltación de la razón y del progreso. La Criminología Posmodema reclama el plura lismo y la diversidad y, más concretamente, que en la criminología o estudio del delito conviven muy distintos paradigmas, que la criminología incluye un abanico multicolor entre las que la criminología Positiva, mayoritaria, es sólo una, pero en ningún caso la única; que hay, en efecto, muy distintas formas de entender la criminología y de a proximarse al delito ${ }^{14}$.

Así, desde el Feminismo Posmodemo se ha criticado la noción de objetividad establecida por las ciencias sociales. Sandra Harding $(1986,1987)^{15}$ señala que esa objetividad de la ciencia es el mundo percibido por los hombres, que lo que aparece como objetividad es realmente el sexismo y que en los tipos de preguntas de las ciencias sociales han estado excluidas sistemáticamente las mujeres y sus intereses. Por consiguiente, desde su concepción de empinsmo feminista la verdadera ciencia no debía ser androcentrica, sino que tomańa en cuenta a ambos géneros. Tal perspectiva no pretende amenazar el orden establecido, sino facilitar el estudio de las mujeres ofensoras para llenar los huecos del conocimiento existente. Harding ve un potencial en el empinismo feminista, y defiende este hecho por la identificación de las diferentes áreas para el estudio, como es el caso de la violencia intrafamiliar, entre otros temas. La base epistemológica de esta forma de conocimiento feminista es la experiencia; sin embargo, no cualquier experiencia se juzga igualmente valiosa, sino aquella que se compromete en la lucha contra la opresión.

\footnotetext{
${ }^{14}$ Serrano, Alfonso, op. cit.

${ }^{15}$ Citado en Smart, Carol, op. cit.
} 
Las contribuciones feministas cuestionaban no sólo las posiciones epistemológicas y prácticas de la criminología tradicional, también desafiaban la idea de objetividad en el sistema de justicia criminal y judicial. De ahí surge la necesidad de develar la verdad de igualdad ante la ley en un rango de estudios empíricos. Algunos estudios parecían encontrar que la policía o cortes trataron a las mujeres igualmente que a los hombres, mientras otros estudios encontraban lo contrario. Había tantos descubrimientos dependiendo de la naturaleza de la ofensa o la longitud del registro o el estado civil del ofensor.

Mackinnon (1987)16 postula que cualquier acercamiento que se centre en la igualdad y la desigualdad siempre presume que la noma son los hombres. De los estudios del sistema de justicia delictivo siempre comparan el tratamiento de mujerescon los hombres, siguen siendo la noma contra todo lo que se juzga.

La pregunta que se hace Smart es si se tiene una criminología realista feminista o si el realismo de izquierda (y por consiguiente la criminología en conjunto) se ha revitalizado por las energías y preocupaciones del movimiento de las mujeres políticamente activas. Esta es una pregunta que la autora deja sin una respuesta clara.

Sin embargo, si deja ver que el Realismo de Izquierda ha sido insuficiente para abordar otra clase de conocimiento, como es el caso de los estudios de masculinidad que han quedado fuera de la investigación. Así el Realismo Feminista está en una tra yec toria diferente del Realismo de Izquierda.

El Posmodemismo feminista no intenta resolver los problemas desde otras posiciones, más bien empieza en un lugar diferente y prosigue en otras direcciones. El feminismo tenía que abandonar su armazón inicial y empezar

\footnotetext{
${ }^{16}$ Citado en Smart, Carol, op, cit.
} 
a buscar otras maneras de prácticas, los debates sobre la sexualidad, la pomografía y los deseos empezaron a deshacer la idea del verdadero ego y dieron la forma a las nociones de subjetividades fracturadas. El elemento central del Posmodemismo feminista es el rechazo de una realidad que se levanta sobre la "falsa perspectiva del discurso universal", buscando acabar con la imposición de una realidad unitaria; más bien se refiere a conocimientos subyugados que cuentan historias diferentes y tienen espec ificida des diferentes.

\section{Conclusiones}

La Criminología Tradicional ignoró los estudios sobre criminalidad femenina y aplicó las mismas teorías y conclusiones de los estudios sobre delincuentes varones a las conductas delictivas de las mujeres. Esto trajo como consecuencia el nulo desarrollo de esta problemática en esta etapa de la criminología.

Con el surgimiento de la Nueva Criminología y del Realismo de Izquierda se puso sobre la mesa de las discusiones temas que se refeńan a la mujer como víctima y como ofensora. La tesis de la liberación pronosticó un cambio en las estadísticas delictivas de las mujeres: habría una mayor participación debido a las posibilidades que se les presentaban ahora por su masiva incorporación al mercado del trabajo; sin embargo, persiste la alta proporción delictiva en los va rones. Las esta dísticas oficiales nos dicen que las mujeres cometen menos infracciones que los hombres, tienen menos probabilidades de ser reincidentes y también de cometer delitos realmente graves ${ }^{17}$.

Otro tema importante que trajo el Rea lismo de Izquierda es el de las víc timas. Estaba preocupado por los efectos del crimen y particulamente por la

\footnotetext{
${ }^{17}$ Rutter, M., Giller, H y Hagel, A., La conducta antisocial de los jóvenes, Edit. Cambridge University Press, Madrid, 1999, 352-385
} 
victimización de las mujeres, como las agresiones en el ámbito familiar, las violaciones y el acoso sexual. Esta línea de estudios generó una sensibilización sobre estas problemáticas y la elaboración e implementación de políticas públicas para la atención especializada sobre los efectos de esta vic timiza ción.

Los nuevos enfoques de la Criminología Feminista, cuestionan los prejuicios ideológicos de la Criminología Tradicional y las limitaciones del Realismo de Izquierda para abordar el tema de la criminalidad de las mujeres. La cuestión ahora es lo penetrante de la dominación masculina en las concepciones teóricas y metodológicas de la criminología. La tarea de las feministas es demostrar que los paradigmas androcentricos permean los "científico", lo "correcto" y lo "determinista" en cuanto al entendimiento de la naturaleza humana y el orden social. Las a utorasCarol Smart y Maureen Cain proponen colocar en un lugar central el tema de las mujeres, quitando la atención en el varón, como el punto de referencia a partir del cual se mide la conducta delictiva de las mujeres. Proponen recumir a conceptos y herramientas metodológicas que se encuentran fuera del discurso criminológico, como la perspectiva de género y los estudios de masculinidad.

El elemento central del Posmodemismo Feminista es el rechazo a aceptar una realidad única, la verdadera ciencia no debe ser androcentica, sino que debe tomar en cuenta a ambos géneros. Es aquí donde se encuentra ahora el debate, falta un camino por andar para poder llegar a explicaciones que den cuenta, a partir del género, de la conducta criminal. 


\section{BIBUOGRAF́A}

Arteaga, Catalina, "Identida des y relaciones de género de chavos banda en la Ciudad de México. Un estudio de caso exploratorio en la delegación Tlalpan", 2000. www.clacso.org

Aza ola, Elena, El delito de sermujer. Hombres y mujeres homicidas en la ciudad de México: historias de vida, Edit. Plaza y Valdez, Méxic o, 1996.

Cain, Maureen, Towa rds transgression: New directions in feminist criminology. Intemational J oumal of the Sociology of Law, 18, 1990, pp.1-18

Freud, Sigmund, Nuevas aportaciones al psicoanálisis, Obras completas, Tomo II, Biblioteca Nueva, Madrid, España, 1948, p.350

Larrauri, Elena, La herencia de la criminología crítica, Edit. Siglo XXI, España, 1992.

Rutter, M., Giller, H y Hagel, A., La conducta antisocial de los jóvenes, Edit. Cambridge University Press, Madrid, 1999.

Serrano, Alfonso, Introducción a la Criminología. UNED, 2da edic., Madrid, 2004.

Smart, Carol, Law, crime and sexuality, Essays in Feminis, Edit. Sage Public ations Ltd, London, 1995.

Urtega, C., Pozo, M., "Flores de a sfalto. Las chavas en las culturas juveniles" en Jóvenes, Revista de estudios sobre juventud, Ciudad de México, cuarta época, año 1, Num. 2, 1996. 